\title{
Malposition of Stent a Rare Complication in Coarctation of Aorta Corrected with Extraanatomic Aortic Bypass
}

\author{
Navnita Kisku, Subrata Pramanik, Kumar Aditya, Subodh Satyarthi \\ Department of CTVS, GB Pant Hospital, New Delhi, India \\ Email: navnita.kisku@gmail.com
}

How to cite this paper: Kisku, N., Pramanik, S., Aditya, K. and Satyarthi, S. (2017) Malposition of Stent a Rare Complication in Coarctation of Aorta Corrected with Extraanatomic Aortic Bypass. World Journal of Cardiovascular Surgery, 7, 164-168. https://doi.org/10.4236/wjcs.2017.712019

Received: November 16, 2017 Accepted: December 18, 2017 Published: December 21, 2017

Copyright (c) 2017 by authors and Scientific Research Publishing Inc. This work is licensed under the Creative Commons Attribution International License (CC BY 4.0).

http://creativecommons.org/licenses/by/4.0/

\begin{abstract}
Mal-position of stent in coarctation of aorta is very rare but a major complication. Symptoms can worsen even more. We present here one such case where stenting done in some other institute in which we did an extra-anatomical bypass from ascending aorta to supracelial aorta successfully bypassing the coarct segment. This was an early approach without assistance of Cadiopulmonary (CP) Bypass. We conclude that this procedure should be done in centres where experienced operator and cardiac surgery back up is present. This was a good approach without assistance of CP Bypass.
\end{abstract}

\section{Keywords}

Coarctation of Aorta, Extra-Anatomical Bypass, Cardio-Pulmonary Bypass

\section{Introduction}

Coarctation of aorta $(\mathrm{CoA})$ is a condition where the aorta is narrow in the area of insertion of ductus arteriosus. If the narrowing is severe enough left ventricle may not be strong enough to push blood through coarctation thus resulting in lack of blood to lower half of body. It's a common congential defect usually detected in childhood but can also present in adulthood. In developed countries, more adults are seen with coarctation than children and a prevalence of $5 \%-8 \%$ of all congenital heart disease is seen [1]. Those presenting late in life have a higher prevalence of morbidity and late complication.

There are different methods describe for the treatment of CoA in adult including surgical or percutaneous balloon angioplasty with or without stent placement. Balloon angioplasty and stent placement is preferred mode of treat- 
ment. Here we present mal-position of stent in a case of CoA for which an extra-anatomical bypass from ascending aorta to supraceliac aorta was done without cardiopulmonary bypass (CPB) assistance.

\section{Case Report}

A 45-year male diagnosed having CoA (Figure 1(a)) underwent stenting of the coarct segment in another institute. Patient presented to us 1 month post-procedure with worsening of symptoms of claudication. On clinical examination there were no gangrenous changes in the lower limb. Ankle brachial pressure index of left limb was 0.5 which suggested significant disease. Computer tomographyangiography (CTA) showed stent below the coarcted segment (Figure 1 (b)). Balloon angioplasty was unsuccessful and showed a mean gradient of 60 $\mathrm{mm} \mathrm{Hg}$.

He was planned for surgical correction with an extra anatomical bypass from ascending thoracic aorta to supraceliac abdominal aorta as the stent was

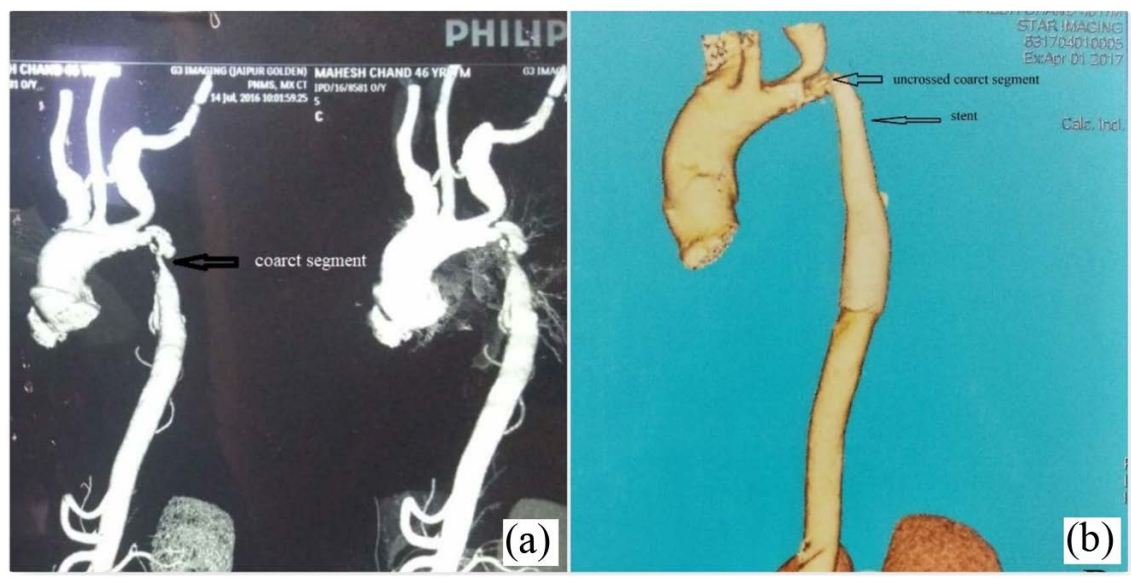

Figure 1. (a) CTA showing CoA before stenting; (b) CTA image after stenting.

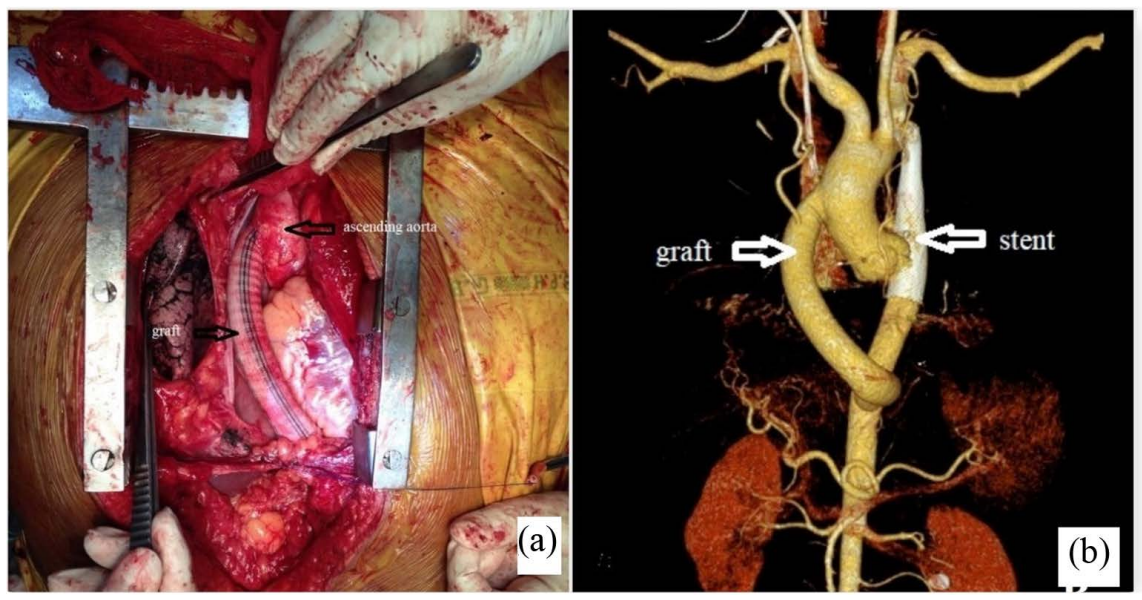

Figure 2. Postoperative image. (a) Graft from ascending aorta passing through diaphragm lying side to right atrium; (b) CTA angiography after surgery showing good flow in graft and lower limb abdominal aorta. 
extending till the diaphragm. Median sternotomy was done. Pericardium opened. Abdomen was exposed by extending the same incision. Peritoneal cavity was entered, left triangular ligament was divided to mobilize left lobe of liver. The gastrohepatic ligament was excised to retract the caudate lobe of liver. Esophagus and upper part of stomach was retracted to left. Posterior peritoneum was reached where the supra-celiac position of aorta was exposed. A side biting clamp was put on ventral side of aorta. A $16 \mathrm{~mm}$ Dacron graft according to body surface area was taken and end to side an astomosis was done to ventral position of aorta. The graft was passed through the diaphragm. Side biting clamp was released and graft was clamped. The proximal end was an astomosed to the right side of proximal ascending aorta using a side biting clamp on the aorta. Graft was placed in such a manner that it lied ventral to inferior venacave and lied lateral to right atrium (Figure 2(a)). Post-procedure gradient was below $15 \mathrm{~mm}$ Hg. Post operative CTA done at the time of follow up showed normal filling of bilateral lower limb arteries (Figure 2(b)). Patient was asymptomatic when patient came 3 months after follow up.

\section{Discussion}

Surgical repair of CoA can be achieved by several surgical techniques. With advancement of intervention cardiology balloon angioplasty either alone or along with stent is the preferred treatment modality [2]. Studies have also shown stenting to have good results with no recoil of vessel wall or re-stenosis or aneurysm formation. Though rare but this procedure can cause major complication such as balloon rupture mal-position of stent, vascular complication of access site and stroke [3].

Our patient was not a good candidate for stent placement. Due to lack of expirence of the cardiologist he tried to stent the segment. But it was deployed distal to coarct segment, which led to worsening of the symptoms and created complication. No similar case is being reported till now. We did an extra anatomical bypass from ascending aorta to supraceliac artery to relive his symptoms. In 1977 Wukasch and colleagues [4] reported extra-anatomical bypass from ascending aorta to supraceliac bare portion of abdominal aorta. Advantage of this procedure is that the supraceliac bare area has less tributaries and least likely to be atherosclerotic thus less likely of bleeding, requires shortest course of graft, less bowl manipulation so less intestinal complication [5].

Connolly et al. described an extra anatomical bypass from ascending aorta to descending aorta entirely through a sternotomy incision with CPB assistant. Major limitation of this approach was bleeding from distal anastomosis because of poor access to distal thoracic aorta, $\mathrm{CPB}$ assistance, retraction of heart to cephalad position, difficult exposure in obese patient and barrel chest [6]. Many technique have been describe previously, but some studies have reported long term outcome with good results [5] [7] [8]. 


\section{Conclusion}

Mal-position of stent in treatment of CoA is a major complication and should be aggressively treated to prevent organ damage. So if possible stenting should be done in centers where experienced operators are available along with cardiac surgery facilities and a good preoperative evalution should be done. Better to do a ballondialatation before stenting so that proper size stent can be placed. The extra anatomical ascending aorta to abdominal aorta bypass graft approach is a safe procedure with no morbidity for this type of complication. Bypass to supraceliac abdominal aorta can be done without $\mathrm{CPB}$ assistance (therefore excluding the complication of $\mathrm{CPB}$ ), preventing injury to phrenic and recurrent laryngeal nerve. Dissection around Distal thoracic aorta can be prevented which can lead to devastating hemorrhage due to multiple collaterals. Risk of ischemic injury to spinal cord is decreased. The main concern is only long incision, division of diaphragm, mobilization and manipulation of liver, esophageal injury.

\section{Classification}

Congenital heart disease in adult.

\section{Conflict of Interest}

None declared. Patient had given his consent for the Case reports to be published.

\section{References}

[1] Baumgartner, H., Bonhoeffer, P., De Groot, N.M.S., et al. (2010) ESC Guidelines for the Management of Grown-Up Congenital Heart Disease (New Version 2010): The Task Force on the Management of Grown-Up Congenital Heart Disease of the European Society of Cardiology (ESC). European Heart Journal, 31, 2915-2957. https://doi.org/10.1093/eurheartj/ehq249

[2] Shaddy, R.E., Boucek, M.M., Sturtevant, J.E., Ruttenberg, H.D., Jaffe, R.B., Tani, L.Y., Judd, V.E., Veasy, L.G., McGough, E.C. and Orsmond, G.S. (1993) Comparison of Angioplasty and Surgery for Unoperated Coarctation of the Aorta. Circulation, 87, 793-799. https://doi.org/10.1161/01.CIR.87.3.793

[3] Mullen, M.J., et al. (2003) Coarctation of Aorta in Adults: Do We Need Surgeons? Heart, 89, 3-5. https://doi.org/10.1136/heart.89.1.3

[4] Wukasch, D.C., Cooley, D.A., Sandiford, F.M., Nappi, G. and Reul Jr., G.J. (1977) Ascending Aorta-Abdominal Aorta Bypass: Indications, Techniques and Report of 12 Patients. The Annals of Thoracic Surgery, 23, 442-448. https://doi.org/10.1016/S0003-4975(10)64164-1

[5] Kumar, M.V., Choudhary, S.K., Talwar, S., et al. (2016) Extraanatomic Bypass to Supraceliac Abdominal Aorta for Complex Thoracic Aorta Obstruction. The Annals of Thoracic Surgery, 101, 1552-1557.

https://doi.org/10.1016/j.athoracsur.2015.10.080

[6] Connolly, H.M., Schaff, H.V., Izhar, U., Dearani, J.A., Warnes, C.A. and Orszulak, T.A. (2001) Posterior Pericardial Ascending-to-Descending Aortic Bypass: An Alternative Surgical Approach for Complex Coarctation of the Aorta. Circulation, 104, I133-I137. https://doi.org/10.1161/hc37t1.094897 
[7] Airan, B., Mehrotra, R., Talwar, K.K., Taneja, K. and Venugopal, P. (1997) Aortoaortic Bypass: Indications, Techniques and Results. Indian Heart Journal, 49, 303-308.

[8] Wang, R., Sun, L.Z., Hu, X.P., et al. (2010) Treatment of Complex Coarctation and Coarctation with Cardiac Lesions Using Extra-Anatomic Aortic Bypass. Journal of Vascular Surgery, 51, 1203-1208. https://doi.org/10.1016/j.jvs.2009.12.027 